\section{Clinical and Radiographic Predictors of Intracerebral Hemorrhage Outcome}

\author{
Fawaz Al-Mufti ${ }^{a, b}$ Ahmad M. Thabet ${ }^{a}$ Tarundeep Singh ${ }^{a}$ \\ Mohammad El-Ghanem $^{\mathrm{a}, \mathrm{b}} \quad$ Krishna Amuluru $^{\mathrm{b}, \mathrm{c}} \quad$ Chirag D. Gandhi ${ }^{\mathrm{d}}$ \\ a Departments of Neurology, Neurosurgery, and Radiology, Rutgers University-Robert \\ Wood Johnson Medical School, New Brunswick, NJ, USA; ${ }^{b}$ Department of Neurosurgery, \\ Rutgers University-New Jersey Medical School, Newark, NJ, USA; 'Department of \\ Interventional Neuroradiology, University of Pittsburgh Medical Center Hamot, Erie, PA, \\ USA; ${ }^{d}$ Westchester Medical Center, New York College of Medicine, Valhalla, NY, USA
}

\author{
Keywords \\ Outcome $\cdot$ Intracerebral hemorrhage $\cdot$ Predictors $\cdot$ Poor prognosis
}

\begin{abstract}
Background: Intracerebral hemorrhage (ICH) represents $10-15 \%$ of all stroke cases in the US annually. Fewer than $40 \%$ of these patients ever reach long-term functional independence, and mortality rate is roughly $40 \%$ at 1 month. Due to the high morbidity and mortality rates after $\mathrm{ICH}$, early detection of high-risk patients would be beneficial in directing the management course and goals of care. This review aims to discuss relevant clinical and radiographic characteristics that can serve as predictors of poor prognosis and examine their efficacy in predicting patient outcomes after ICH. Summary: A literature review was conducted on various clinical and radiographic factors. They were examined for their predictive value in relation to ICH outcome. Studies that focused on each of these factors were included, and their results analyzed for trends with regard to incidence, patient outcome, and mortality rate. Key Message: In this review, we examined clinical and radiographic characteristics that have been found to be significantly associated to a varying degree with poor outcome. Clinical and radiographic predictors of poor patient outcome are invaluable when it comes to identifying high-risk patients and triaging accordingly as well as guiding decision-making.
\end{abstract}

(c) 2018 S. Karger AG, Basel 


\section{Introduction}

Intracerebral hemorrhage (ICH) represents $10-15 \%$ of all 700,000 strokes in the US every year [1]. ICH is a potentially devastating neurologic emergency with long-term functional independence achieved in only $12-39 \%$ of cases and mortality rates of $54 \%$ at 1 year [2]. Large retrospective cohort studies have shown a significant improvement in mortality rates since 2000 [3], although a meta-analysis of studies between 1980 and 2008 did not show a significant difference in those rates [4].

Prognosis depends on the severity of the clinical presentation, speed of diagnosis, and time of intervention. Due to the nature of ICH to often go unnoticed, prevention may be the most effective approach in lessening the impact ICH has on morbidity [5]. Some risk factors are nonmodifiable, like old age, African-American and Asian ethnicities, male gender, vascular anomalies, and neoplasms; while others are modifiable, like hypertension, coagulopathy, heavy alcohol intake, and illicit drug use.

ICH can be broken down into a few key checkpoints: (1) initial hemorrhagic insult, (2) hematoma expansion, and (3) generalized cerebral edema [6]. Initial hemorrhage is a result of ruptured diseased vessels within the brain. Blood extravasation then leads to formation of a localized edema. The progression from this stage, mainly hematoma expansion and edema, determines patient outcomes. Over the course of hours, bleeding continues leading to progressive accumulation of blood within the brain tissue. Hematoma growth has been determined to occur in a cascaded fashion. Blood extravasation continues from the site of origin and secondary mechanical stresses create rupture of peripheral vessels, leading to ongoing hemorrhage [7]. Expansion creates an increased intracranial pressure that can lead to tissue displacement and potential herniation [8]. Over days after onset, perihematomal edema (PhE) forms secondary to inflammatory processes and oncotic forces [9].

Due to the high morbidity and mortality rates after ICH, early detection of high-risk patients would be beneficial in directing the management course and goals of care. This review aims to discuss relevant characteristics that can serve as predictors of poor prognosis and examine their efficacy in predicting patient outcomes after ICH.

\section{Methods}

A literature review was conducted using PubMed, Cochrane, and Google Scholar database searches for original prospective, retrospective, and observational studies on ICH factors (clinical and radiographic) as predictors of outcome, which were published in English. Search was performed using the following terms in varied combinations: "intracerebral hemorrhage, outcome, predictors, spot sign, neutrophil lymphocyte ratio, swirl sign, hemorrhagic stroke, nontraumatic intracerebral hemorrhage, Glasgow Coma Scale (GCS), perihematomal edema ( $\mathrm{PhE}$ ), intraventricular hemorrhage (IVH)." The authors reviewed full texts and reference lists from relevant papers to identify further articles. In some instances, relevant papers from outside the initial search parameters were included if there seemed to be a lack of more current evidence. Studies that focused on each of these factors were analyzed for trends with regard to incidence, patient outcome, and mortality rate.

\section{Results}

A total of 51 publications were included, 17 are on radiographic factors and 34 on clinical factors: 4 on patients' age, 1 on premorbid function state, 3 on initial Glasgow Coma Scale (GCS), 2 on early changes in code status, 7 on systolic blood pressure (SBP), 4 on coagulopathy, 4 on seizures, 4 on fever, 3 on neutrophil/lymphocyte ratio (NLR), 2 on serum 
fibrinogen level, 2 on hematoma volume, 2 on hematoma expansion, 3 on radiographic spot sign, 4 on swirl sign, 2 on PhE, 3 on intraventricular hemorrhage (IVH) extension, and 1 on hydrocephalus. Study populations, design aspects, and main findings with statistical results of these studies are summarized in Tables $1,2$.

\section{Clinical Predictors of Poor Outcome}

\section{Age}

Old age is both a risk factor for ICH incidence and a predictor of worse outcome. ICH incidence increases with age (relative risk increase of 1.97 per decade) [10] and is expected to rise with the increase in the overall population age [1].

Numerous studies have demonstrated correlation between age and poor outcome after ICH; however, it is often hard to distinguish between age itself and associated comorbidities, like altered cognitive function and hypertension [11]. Bagg et al. [11] examined age as it relates to functional outcome using a Functional Independence Measure (FIM) instrument scale. Age alone was an independent predictor $(p<0.001)$ of poor functional outcome when measured via total FIM score and Motor FIM score. This association, as indicated earlier, may be explained by comorbidities associated with natural aging. A study by Gonzalez-Perez et al. [4] assessed 30-day mortality as it relates to age of admission. Results showed that age not only increased the prevalence of ICH, but also the 30-day mortality rate. Mortality rate increased from $29.7 \%$ in patients aged $20-49$ to $54.6 \%$ in patients aged $80-89$. Age-related mortality rate increased nearly linearly between these two groups $(p<0.0001)$ [4]. Similar findings were reported in a prospective analysis of 549 patients with ICH by Sacco et al. [12], in which older age was associated with an increased risk of 30-day mortality (OR $=1.18, p<$ $0.001)$.

\section{Premorbid Functional State}

The FUNC score was created to predict the likelihood of a patient reaching functional independence after an ICH. Assessed at admission, it takes into account a patient's pre-ICH cognitive impairment, in addition to his age, GCS score, ICH volume, and ICH location. In developing the FUNC score, 418 patients with ICH and 90-day outcome data were studied by Rost et al. [13] to examine the correlation between these predictors and a patient's dependence status at 90 days. In their study, $85 \%$ of patients with a FUNC score of 11 reached functional independence. On the other hand, only $4 \%$ of patients with a score of 5 achieved independence, and there were no patients with a score of 4 or lower who did. Of the components in the FUNC score, age, GCS, ICH volume, IVH, warfarin use, and pre-ICH cognitive impairment were significantly associated with functional independence $(p<0.01)$. Pre-ICH cognitive impairment was identified as an independent predictor of worse outcomes following ICH. The role of premorbid functional status in rehabilitation following stroke could explain the association of pre-ICH cognitive impairment with worse outcomes due to patients starting at a lower baseline [13].

\section{Initial GCS}

ICH is often associated with symptoms and signs of elevated intracranial pressure including decreased level of consciousness that may progress into coma [14]. The GCS is invaluable in assessing patient state of consciousness. More than $20 \%$ of ICH patients will deteriorate by 2 or more points in their GCS score between initial assessment by emergency medical services and arrival to an emergency department (ED) [15]. This drop has been termed ED neurological deterioration. Another 15-23\% of patients will continue to deteri- 


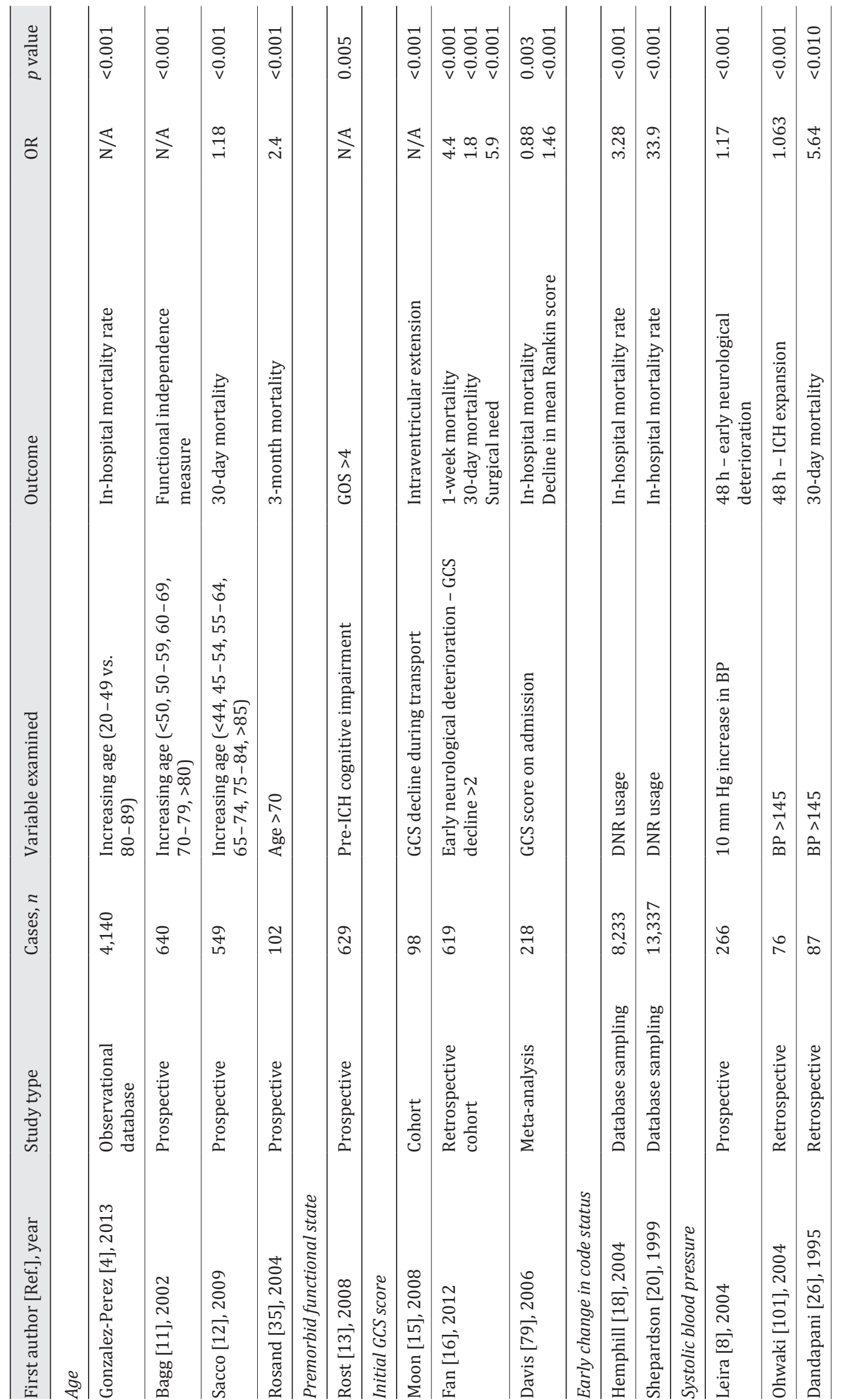




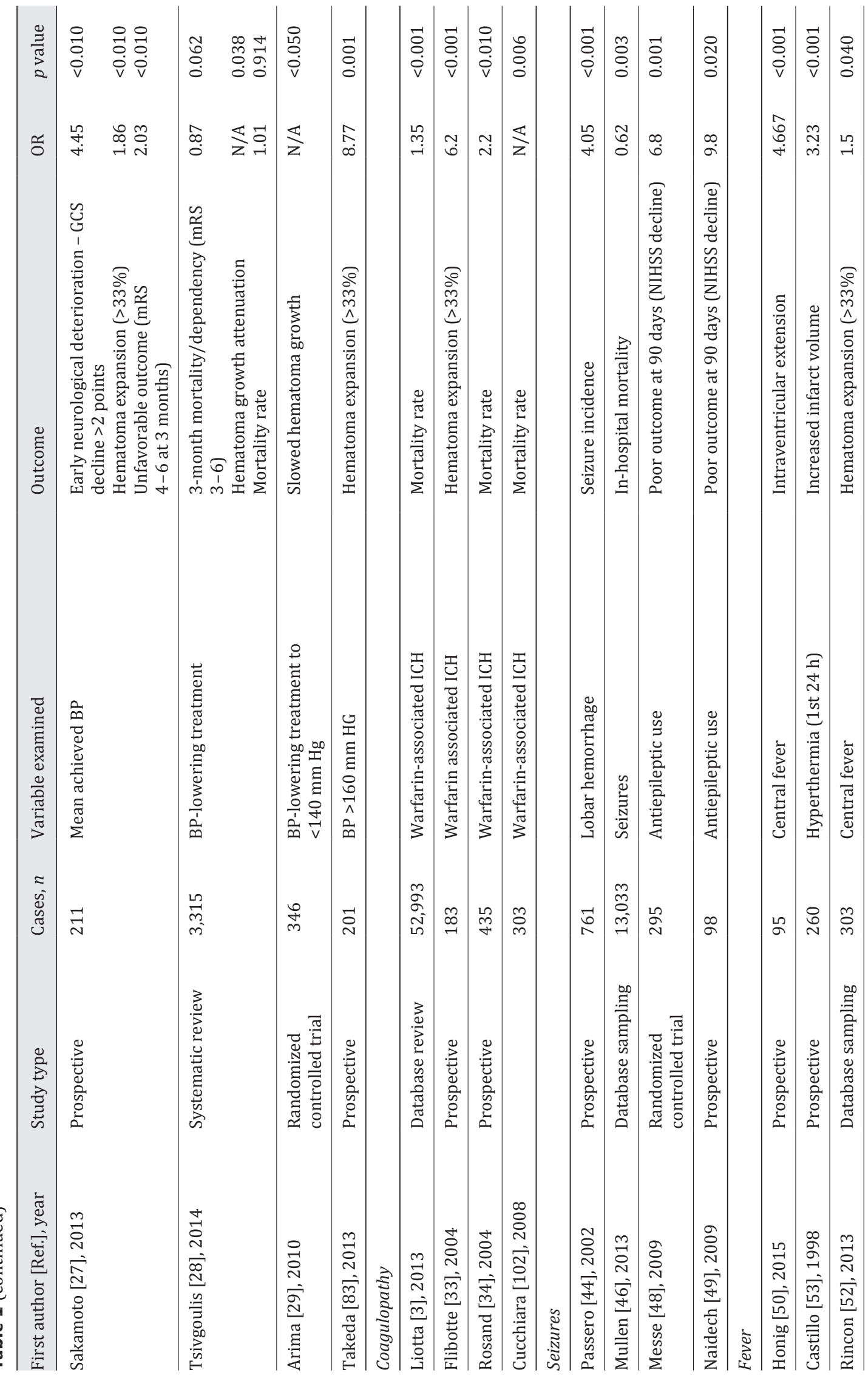




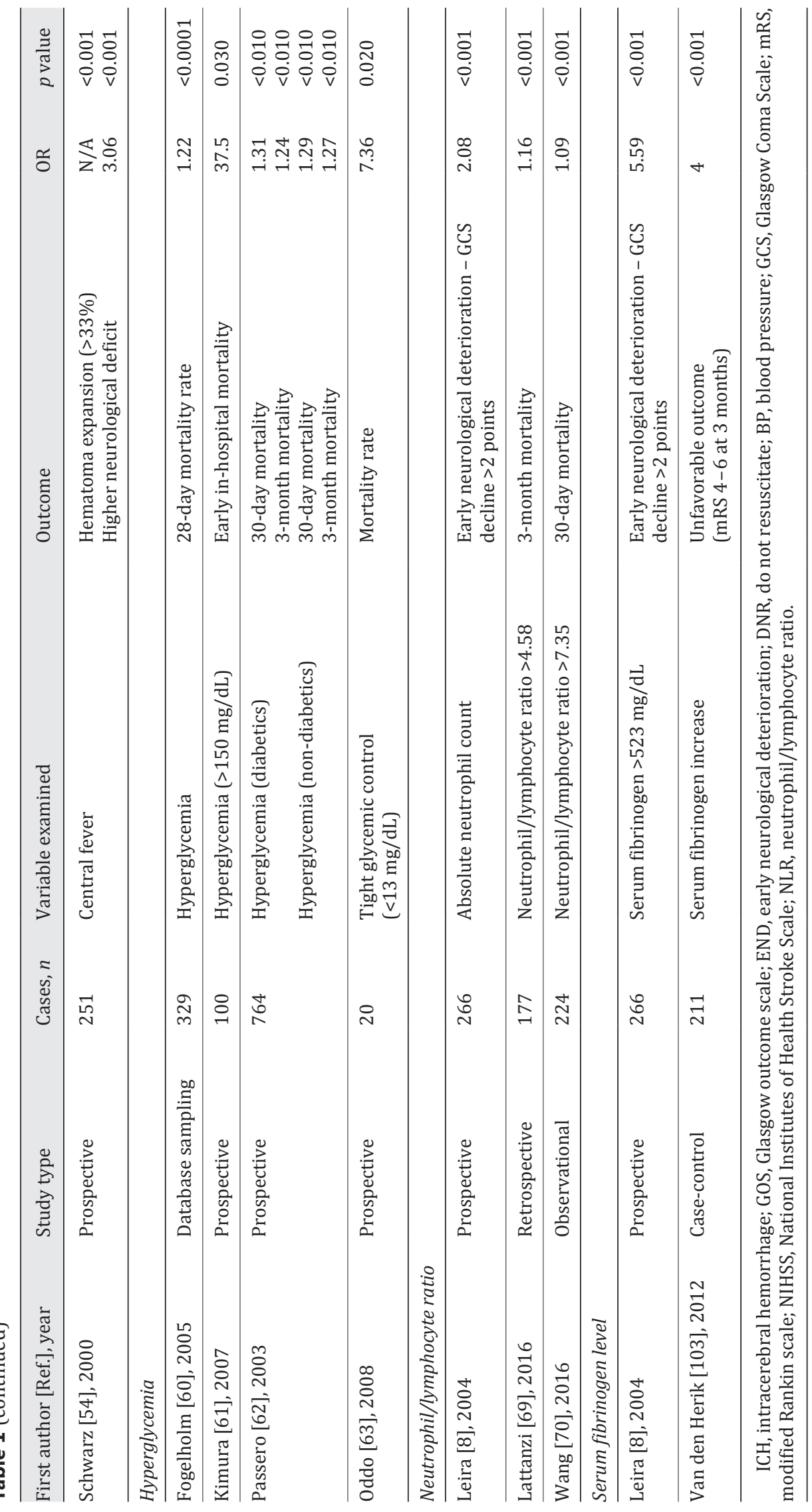




\section{Interventional Neurology}

Al-Mufti et al.: Clinical and Radiographic Predictors of Intracerebral Hemorrhage Outcome

Table 2. Radiographic predictors of poor outcome

\begin{tabular}{|c|c|c|c|c|c|c|}
\hline $\begin{array}{l}\text { First author [Ref.], } \\
\text { year }\end{array}$ & Study type & $\begin{array}{l}\text { Cases, } \\
n\end{array}$ & Variable examined & Outcome & OR & $p$ value \\
\hline \multicolumn{7}{|l|}{ Hematoma location } \\
\hline Broderick [77], 1993 & Retrospective & 188 & $\begin{array}{l}\text { Lobar hemorrhage } \\
\text { Deep hemorrhage } \\
\text { Pontine hemorrhage } \\
\text { Cerebellar hemorrhage }\end{array}$ & $\begin{array}{l}\text { 30-day mortality } \\
\text { 30-day mortality } \\
\text { 30-day mortality } \\
\text { 30-day mortality }\end{array}$ & $\begin{array}{l}39 \% \\
45 \% \\
44 \% \\
64 \%\end{array}$ & $\begin{array}{l}\text { N/A } \\
\text { N/A } \\
\text { N/A } \\
\text { N/A }\end{array}$ \\
\hline \multicolumn{7}{|l|}{ Hematoma volume } \\
\hline Broderick [77], 1993 & Retrospective & 188 & Volume $>60 \mathrm{~cm}^{3}$ & 30-day mortality & $\mathrm{N} / \mathrm{A}$ & $<0.0001$ \\
\hline Takeda [83], 2013 & Prospective & 201 & Volume $>16 \mathrm{~mL}$ & Hematoma expansion $>33 \%$ & 5.05 & 0.018 \\
\hline \multicolumn{7}{|l|}{ Hematoma expansion } \\
\hline Leira [8], 2004 & Prospective & 266 & Hematoma expansion & $\begin{array}{l}\text { Early neurological } \\
\text { deterioration }\end{array}$ & $\mathrm{N} / \mathrm{A}$ & $<0.010$ \\
\hline Davis [79], 2006 & Meta-Analysis & 218 & Hematoma expansion & In-hospital mortality & 1.05 & $<0.001$ \\
\hline \multicolumn{7}{|l|}{ Spot sign } \\
\hline Wada [78], 2007 & Prospective & 39 & Spot sign & Hematoma expansion $>33 \%$ & 8.5 & 0.003 \\
\hline $\begin{array}{l}\text { Tsukabe [84], } \\
2014\end{array}$ & Prospective & 83 & $\begin{array}{l}\text { Spot sign } \\
\text { (on admission) } \\
\text { Spot sign } \\
\text { ( } 48 \mathrm{~h} \text { follow-up) }\end{array}$ & $\begin{array}{l}\text { Hematoma expansion }>33 \% \\
\text { Hematoma expansion }>33 \%\end{array}$ & $\begin{array}{l}\mathrm{N} / \mathrm{A} \\
\mathrm{N} / \mathrm{A}\end{array}$ & $\begin{array}{l}<0.001 \\
<0.00001\end{array}$ \\
\hline Rizos [85], 2013 & Prospective & 101 & Spot sign & Hematoma expansion $>33 \%$ & 5.27 & $<0.001$ \\
\hline \multicolumn{7}{|l|}{ Swirl sign } \\
\hline Boulois [7], 2016 & Cohort & 1,029 & $\begin{array}{l}\text { Hematoma } \\
\text { heterogeneity }\end{array}$ & Hematoma expansion $>33 \%$ & 3.42 & $<0.001$ \\
\hline Barras [86], 2009 & Prospective & 90 & $\begin{array}{l}\text { Hematoma } \\
\text { heterogeneity }\end{array}$ & Hematoma expansion $>33 \%$ & $\mathrm{~N} / \mathrm{A}$ & $<0.046$ \\
\hline Takeda [83], 2013 & Prospective & 201 & $\begin{array}{l}\text { Hematoma } \\
\text { heterogeneity }\end{array}$ & Hematoma expansion $>33 \%$ & 7.81 & 0.004 \\
\hline Selariu [104], 2012 & Prospective & 203 & Swirl sign & 30-day mortality & 2.6 & $<0.001$ \\
\hline \multicolumn{7}{|l|}{ Perihematomal edema } \\
\hline Gebel [87], 2002 & Prospective & 142 & $\begin{array}{l}\text { Baseline relative edema } \\
\text { volume }\end{array}$ & Poor 3-month outcome & $\begin{array}{l}0.09 \\
\text { per } 1 \mathrm{~mL} \\
\text { increase }\end{array}$ & 0.016 \\
\hline Staykov [88], 2011 & Prospective & 219 & Increase in PHE volume & In-hospital mortality & $\mathrm{N} / \mathrm{A}$ & 0.014 \\
\hline \multicolumn{7}{|c|}{ Intraventricular hemorrhage } \\
\hline Leira [8], 2004 & Prospective & 266 & $\begin{array}{l}\text { Intraventricular } \\
\text { hemorrhage }\end{array}$ & $\begin{array}{l}\text { Early neurological } \\
\text { deterioration }\end{array}$ & 2.66 & $<0.01$ \\
\hline $\begin{array}{l}\text { Bhattathiri [95], } \\
2006\end{array}$ & Prospective & 1,033 & $\begin{array}{l}\text { Intraventricular } \\
\text { hemorrhage }\end{array}$ & Poor 3-month outcome & $\mathrm{N} / \mathrm{A}$ & $<0.00001$ \\
\hline Hallevi [96], 2008 & Retrospective & 406 & $\begin{array}{l}\text { Intraventricular } \\
\text { hemorrhage }\end{array}$ & $\begin{array}{l}\text { Poor outcome } \\
\text { (mRS 4-6) }\end{array}$ & 2.25 & 0.001 \\
\hline \multicolumn{7}{|l|}{ Hydrocephalus } \\
\hline Diringer [100], 1998 & Prospective & 81 & Hydrocephalus & 90-day mortality rate & 1.26 & $<0.0001$ \\
\hline
\end{tabular}

PHE, perihematomal edema; IVH, intraventricular hemorrhage; mRS, modified Rankin scale. 
orate within the first few hours of hospitalization [16]. Decline in GCS in the ED was found to be independently associated with a 4.4-fold increase in 1-week mortality $(11.0 \mathrm{vs.} 2.5 \%, p<$ 0.001 ), 1.8-fold increase in 30-day mortality (36.4 vs. $19.6 \%, p<0.001$ ), and a 5.9-fold increased need for surgical intervention (65 vs. 11.1\%, $p<0.001$ ) [16]. The 2015 American Heart Association/American Stroke Association (AHA/ASA) Guidelines for the Management of Spontaneous ICH recommend that standardized disease severity scores such as the GCS and ICH score should be utilized to help facilitate clear communication between medical providers [17].

\section{Early Change of Code Status}

Do-not-resuscitate (DNR) orders are common in the setting of patients with neurological impairment. Many studies have found associations between DNR usage in hospitals and poor patient outcomes after spontaneous ICH. A multicenter study of 8,233 patients found that usage of DNR orders varied greatly across the hospitals studied. Hospitals were broken down into quartiles based on DNR use. Mortality rate increased significantly with DNR usage ( $p$ trend $=0.01$ ). After adjusting for race, age, gender, insurance, and use of mechanical ventilation, every 10\% increase in DNR use rate increased the mortality rate by $13 \%$ [18]. Hospitals reporting the lowest DNR use were more likely to be teaching hospitals or trauma centers. Being made DNR within $24 \mathrm{~h}$ after admission increased mortality rate 2.4, 2.6, 2.8, and 3.3-fold $(p<0.001)$ in quartiles $1,2,3$, and 4, respectively. An increase in DNR use was an independent predictor of patient mortality as compared to an individual lacking a DNR order [19]. It suggests that the mortality risk of patients treated in high DNR use hospitals is related to an aspect of the medical care provided there. Similarly, Shepardson et al. [20], in 13,337 consecutive stroke admissions across 30 hospitals, noted that DNR usage was associated with a higher in-hospital mortality rate compared to those patients without a DNR order ( $40 \mathrm{vs.} 2 \%$, $p<0.001$ ). Other studies focused on the potential relation between withdrawal of care discussion and probability of poor outcome. In a retrospective analysis of 383 patients with multiple types of intracranial hemorrhage, Weimer et al. [21] explored whether withdrawal of life support therapy decision would accurately identify patients with high probability of poor outcome. The results showed that the majority of patients undergoing withdrawal of life support therapy may be expected to have either died or remained significantly disabled despite maximum therapy. When stratifying by hemorrhage type, ICH was associated with high median predicted probability of poor outcome and death.

\section{Systolic Blood Pressure}

Hypertension is the most common cause of primary ICH, accounting for $60-70 \%$ of all cases [22]. A history of hypertension, in a trial of 370 patients, was determined to double the risk of ICH occurrence (OR $=2.55,95 \%$ CI 1.72-3.79) [23]. Chronic hypertension leads to reduced elasticity of deep small arterioles and increased susceptibility to spontaneous rupture [24]. Common locations for hypertension-related ICH are the putamen (46\% of all ICH patients), thalamus (18\%), caudate (4\%), pons (13\%), and cerebellum (4\%) [25].

After the initial insult, sustained hypertension in the early stages of ICH can create a risk of continuous hemorrhage, increased ICH volume, and worsened severity of the stroke [26]. In a study by Sakamoto et al. [27] $(n=211)$, a $10 \mathrm{~mm} \mathrm{Hg}$ increase in uncontrolled SBP was found to be associated with poor outcomes. Outcomes assessed were early neurological deterioration ( $\mathrm{OR}=4.45,95 \% \mathrm{CI} 2.03-9.74)$, hematoma expansion ( $\mathrm{OR}=1.86,95 \% \mathrm{CI} 1.09-3.16)$, and unfavorable outcome measured by a Rankin disability scale score of $4-6$ (OR $=2.03,95 \%$ CI 1.24-3.33).

Antihypertensive medications were noted to ameliorate the incidence of ICH and associated poor outcomes. A meta-analysis of 3,315 patients showed that intensive BP reduction 
was found to be associated with lower unfavorable 3-month functional outcomes and mortality. In addition, they found that blood pressure reduction was associated with quicker attenuation of hematoma growth and ICH progression [28]. Significant associations have been noted between aggressive SBP reduction within $24 \mathrm{~h}$ and attenuation of hematoma growth $(p<0.05)$. In a study by Arima et al. [29], SBP reduction to between 130 and $140 \mathrm{~mm}$ $\mathrm{Hg}$ within $24 \mathrm{~h}$ of admission with ICH, showed the highest protective effect against hematoma growth. The Intensive Blood Pressure Reduction in Acute Cerebral Hemorrhage Trial (INTERACT) found that intensive lowering of SBP to $<140 \mathrm{~mm} \mathrm{Hg}$ significantly reduced the risk of poor outcomes $(p<0.05)$. In addition, intensive blood pressure-lowering showed no significant adverse effects [30]. To further study the efficacy of early, intensive antihypertensive treatment, the NIH had funded the Antihypertensive Treatment of Acute Cerebral Hemorrhage trial (ATACH-II). This trial enrolled 1,000 patients within $4.5 \mathrm{~h}$ of ICH, a hematoma volume $<60 \mathrm{~mL}$, and SBP $>180 \mathrm{~mm} \mathrm{Hg}$. Whereas INTERACT2 results suggested a benefit of blood pressure lowering, ATACH-II did not [31]. The difference lay in the more rapid and intensive lowering of SBP in the ATACH-II trial. Combined results suggest that blood pressure reduction to $140 \mathrm{~mm} \mathrm{Hg}$ is beneficial but more so in a controlled manner like in INTERACT2 $[30,31]$. The 2015 AHA/ASA ICH guidelines recommend targeting an SBP goal of $<140 \mathrm{~mm}$ $\mathrm{Hg}$ for ICH patients with a presenting SBP between 150 and $220 \mathrm{~mm} \mathrm{Hg}$ and no contraindication for treatment, and that it is reasonable to lower SBP for patients who present with an SBP $>220 \mathrm{~mm} \mathrm{Hg}$, but a specific target blood pressure is not specified [17].

\section{Coagulopathy}

Coagulopathy is a risk factor for primary ICH. 6.6\% of ICH patients in the US from 2005 to 2008 were using warfarin [3]. Novel oral anticoagulants (NOACs) have a lower risk of ICH than warfarin. Other causes of coagulopathy include platelet deficiency or dysfunction, congenital or acquired coagulation factor deficiencies, and liver disease [32].

Coagulopathy is also associated with worse ICH outcomes, commonly in the setting of the use of vitamin K antagonists [3, 33, 34]. The risk of ICH occurrence and expansion is higher with warfarin and the NOAC than with antiplatelet agents [35]. Although randomized trials in atrial fibrillation patients showed that NOACs have about half the incidence of ICH compared to warfarin [36], subsequent studies noted that baseline ICH volume, hematoma expansion, mortality, and functional outcome at 90 days were similar following NOAC-associated ICH and vitamin K antagonist-associated ICH [37].

In terms of outcomes, warfarin has been noted to significantly increase the ICH-related 30-day mortality rate in multiple studies. Rosand et al. [34] observed a doubling in mortality rate in patients on warfarin therapy, 52 compared to 25.8\%. Liotta and Prabhakaran [3] ( $n=$ $52,993)$ discovered in their review of warfarin-associated ICH (WAICH), that incidence rose from 2005 to 2008 by $2 \%$ and was associated with a 35\% higher mortality rate than nonWAICH patients (OR $=1.35,95 \%$ CI $1.24-1.47, p<0.001)$. Another study of 183 cases by Flibotte et al. [33] supports these findings; warfarin was the sole predictor of hematoma expansion $(\mathrm{OR}=6.2,95 \% \mathrm{CI} 1.7-22.9, p<0.001)$ and consequent patient mortality rate. Since WAICH expansion occurs rapidly, abrupt reversal with vitamin $\mathrm{K}$ in addition to fresh frozen plasma (FFP) or prothrombin complex concentrate (PCC) may be crucial in stopping progression and improving outcomes [38,39]. Not only PCC provides rapid administration and INR correction compared to FFP, in one study its use was associated with improved 3-month outcome in patients with WAICH [40]. In patients with factor Xa inhibitor-associated ICH, the available data are not sufficient to support the efficacy of available reversal agents. Nevertheless, the neurocritical care society and society of critical care medicine advises the administration of reversal agents to correct anti-factor Xa-associated coagulopathy. Due to better correction and lower risk of thromboembolism, it seems favorable to use 4-factor PCC or acti- 
vated PCC. Regarding direct thrombin inhibitor-associated ICH, it is recommended to use idarucizumab (5 g i.v. in two divided doses) as the reversal agent. Other methods of reversal are the use of PCC and or dialysis in certain patients or if idarucizumab is not available [41].

\section{Seizures}

The incidence of seizures after ICH is roughly $15-20 \%$, most of which are nonconvulsive in nature $[42,43]$. Seizures after ICH can be divided clinically into early onset $(<2$ weeks) or late onset ( $>2$ weeks), and their origin varies. Early-onset seizures are thought to be due to a sudden mass development within the brain parenchyma that disrupts the brain's natural architecture. Late-onset seizures after ICH are mechanistically described as irregular electrical activity due to scar tissue formation [44].

In a large clinical series, 761 patients with spontaneous ICH were observed for occurrence of seizure, the predictive value it may hold, and the utility of prophylactic antiepileptic therapy. Seizures occurred in $4.2 \%$ of all patients $(n=761)$ within $24 \mathrm{~h}$ ("immediate") and in $8.1 \%$ within 30 days after ICH ("early"). Immediate seizures, occurring within $24 \mathrm{~h}$, were associated with smaller hematoma volumes, and with lobar ICH. Analysis showed that lobar location of hemorrhage held the most predictive value for immediate seizures (OR $4.05 ; p<$ 0.00001 ) [45]. Another study by Neshige's group analyzed data from 1,920 patients after ICH and confirmed the associations made by Passero et al. [45] showing significant relationships between seizures and lobar/cortical hemorrhage $(p<0.001)$, nonhypertensive ICH $(p<$ $0.001)$, and neurological deficits $(p<0.001)$.

Though prevalence is high, the impact seizures have on patients' prognosis is unclear. Some studies have found that seizures in the setting of acute ICH do not negatively affect outcomes $[43,45,46]$ while others have found that they were associated with worse outcomes $[46,47]$. Likewise, studies of the impact of anticonvulsant medications in ICH have had conflicting results. Passero et al. [45] reported that antiepileptic drugs (AED) significantly reduced clinical seizures after lobar ICH. In contrast, several studies have reported a lack of effect of AED especially in the acute period. Furthermore, worse outcome was noted especially with the use of phenytoin $[48,49]$. The 2015 AHA/ASA ICH guidelines recommend that ICH patients with an unexpected decreased level of consciousness should be screened for electrographic seizures with continuous EEG monitoring, and recommend against prophylactic AEDs, but do recommend that clinical and electrographic seizures in patients with a decreased level of consciousness should be treated with AEDs [17].

\section{Fever}

Fever has been reported in $30-40 \%$ of all ICH cases [50,51], which may be secondary to an infection or neurogenic. Infection-related fever is the most prevalent, and it could be due to a concurrent or hospital-acquired infection [51]. In that study, 37.6\% of ICH patients were febrile; $22.7 \%$ of patients had a documented infection; while $14.8 \%$ developed fever without an infection [51]. Neurogenic fever is a diagnosis of exclusion with no identified causative agent. Initial hemorrhage and the associated mass effect of the hematoma, have been hypothesized to induce neuronal and cell death leading to an inflammatory state that leads to an elevation in body temperature [52]. It could also be due to lesions at the anterior region of the hypothalamus, which regulates temperature [53]. Fever has been noted to be more prevalent following lobar or basal ganglia ICHs, with the highest prevalence if IVH is present [54, 55]. There is also evidence to support that intracranial temperature is significantly higher in ICH patients as compared to core temperature, correlated with a rise in intracranial pressure.

Fever has been described to directly impact neurological decline [56]. It has been associated with both hematoma expansion and worse outcomes [54, 57]. Rincon et al. [52] analyzed the effect of a rise in temperature at admission and then $24,48,72$, and $168 \mathrm{~h}$ after 
ICH on patient outcome. A cumulative change rise in temperature at $72 \mathrm{~h}$ was associated with increased hematoma expansion and poor outcome at 90 days. Another study included 251 patients to investigate the prognostic significance of fever on admission and following $72 \mathrm{~h}$ in spontaneous ICH. $9 \%$ of patients had normal temperatures through the 72-h study. Of the rest, fever duration was $<24 \mathrm{~h}$ in $34 \%, 24-48 \mathrm{~h}$ in $36 \%$, and $>48 \mathrm{~h}$ in $21 \%$. Increased duration of fever was significantly associated with significantly worse outcome as assessed on discharge with the Glasgow Outcome Scale (GOS) score [54]. The 2015 ICH guidelines recommend treating fever in the setting of ICH, although current studies have failed to show improved outcomes with controlled normothermia in this setting $[58,59]$.

\section{Hyperglycemia}

Hyperglycemia in ICH patients has been associated with worse outcomes in several studies [60-62]. Kimura et al. [61] aimed to examine the association of plasma glucose and the risk for early death in 100 patients. Admission plasma glucose levels were significantly higher in patients who died within 14 days as compared to those who survived $(p<0.0001)$. Glucose levels $>150 \mathrm{mg} / \mathrm{dL}$ were independent predictors of early death. Amongst 764 patients with ICH, Passero et al. [62] found that high plasma glucose was associated with greater incidence of infectious and cerebral complications and also served as an independent predictor of 30-day and 3-month mortality. High blood glucose levels on admission were associated with more severe strokes, supporting evidence that hyperglycemia is associated with poor patient outcomes $[61,62]$. However, the concern has been raised that aggressive treatment of elevated blood glucose may lead to systemic or cerebral hypoglycemia and potentially worsen outcomes [63-65]. Tight glycemic control is achieved with intensive insulin therapy with variable target ranges. In a study by Oddo et al. [63], two target levels were categorized: "tight" (80-120 mg/dL) and "intermediate" (121-180 mg/dL). The patients under "tight" control had increased prevalence of low plasma glucose levels (65 vs. 36\% in "intermediate," $p<0.01$ ) and brain energy crisis (25 vs. $17 \%$ in "intermediate," $p<0.01$ ). Brain energy crisis, a condition of starvation where brain function is reduced, was defined as a glucose level $<13$ $\mathrm{mg} / \mathrm{dL}$. This state was associated with an increased mortality rate [63]. However, Vespa et al. [64] found that intensive therapy does not offer functional outcome or mortality advantage. The 2015 AHA/ASA ICH guidelines recommend close monitoring of the glucose level and avoiding either hyperglycemia or hypoglycemia [17].

\section{Neutrophil/Lymphocyte Ratio}

NLR is used as a marker for inflammation within the vascular bed, a commonly hypothesized mechanism for injury in ICH [66,67]. Within hours after the initial insult, neutrophils are recruited around the growing hematoma and contribute to cellular injury. As such, the increase in NLR holds predictive value as to the severity of the hemorrhagic insult in ICH and existing inflammatory changes [68].

Several studies have examined the correlation between NLR and patient outcome after ICH. A study of 177 patients by Lattanzi et al. [69] examined the predictive value of NLR in terms of patient outcome. An absolute neutrophil count above the upper limit, and absolute lymphocyte count below the lower limit, and NLR $>4.58$ as defined by the study were independently associated with 1.7 - and 2 -fold increase in 90-day mortality (OR $=1.22,0.57,1.16$, respectively; $p<0.001$ each). Another study of 224 patients by Wang et al. [70] found that an NLR $>7.35$ was associated with a significantly higher mortality rate; 31.6 compared to $4.8 \%$ in those with an NLR $<7.35$ upon admission. In those surviving ICH, Leira et al. [8] found that absolute neutrophil count was an independent predictor of early neurological deterioration. Various studies demonstrate that NLR holds predictive value for patient outcome due to its correlation with severity of inflammation; however, they differ on significant NLR cutoffs. 


\section{Serum Fibrinogen Level}

Serum fibrinogen level is a measure of blood coagulation and also an acute phase reactant. Like NLR, fibrinogen level is reflective of the level of inflammation and tissue damage around the hematoma. In a study using univariate analysis with logistic regression model, serum fibrinogen level $>523 \mathrm{mg} / \mathrm{dL}$ was found to be significantly associated with early neurological degeneration $(p<0.001)$ [8]. Another study of 135 ICH events, using a multivariable model, found that for every standard deviation increase $(66.2 \mathrm{mg} / \mathrm{dL})$ in serum fibrinogen, there was a 1.35-fold greater risk of ICH occurrence $(p<0.001)$ [71]. Increased absolute fibrinogen levels were found to be associated with unfavorable outcomes.

\section{Radiographic Predictors of Poor Outcome}

Noncontrast computerized tomography (CT) is the most widely used tool for the diagnosis and evaluation of ICH. Head CT scan helps defining the hematoma location, size, and associated IVH and hydrocephalus. These properties of a hematoma and the ongoing hemorrhage have been shown to be effective for predicting patient prognosis.

\section{Hematoma Location}

The 30-day mortality rate in ICH is between 44 and 51\%, with variation based on the location and volume of the hemorrhage [72]. Deep hemorrhages consist of those originating in the basal ganglia, thalamus, internal capsule, cerebellum, brain stem, or ventricles. In these hemorrhages, blood accumulation leads to hematoma expansion within the brain's white matter, adjacent to the ventricular system. Lobar hemorrhages, usually secondary to amyloid angiopathy, are those originating in the cortex and subcortical white matter. The risk of recurrence of ICH is higher in cases associated with cerebral amyloid angiopathy $110-20 \%$ per year) [73] as compared to cases associated with hypertension $(<2 \%$ per year, if hypertension is well controlled) [74]. As a whole, independent of hemorrhage volume, cerebellar ICH was the highest predictor of 30-day mortality rate, considering the limited space in the posterior fossa and higher risk of herniation.

\section{Hematoma Volume}

For any given location in the brain, the volume of ICH is the strongest predictor of 30-day mortality rates. While planimetric computerized methods can be used, hematoma volume can be "hand calculated" quite accurately using the $\mathrm{ABC} / 2$ method which estimates the volume of a spheroid [75, 76].

In a study of 30-day mortality rates based on ICH volume, Broderick et al. [77] found that ICH volumes $<30 \mathrm{~cm}^{3}$ showed the following 30-day mortality rates: 57 for cerebellar, 23 for deep, and $7 \%$ for lobar, while ICH volumes between 30 and $59 \mathrm{~cm}^{3}$ showed the following rates: 75 for cerebellar, 64 for deep, 60 for lobar, and 100\% for pontine; and finally ICH volumes $>60 \mathrm{~cm}^{3}$ showed the following rates: 93 for deep and $71 \%$ for lobar (no cerebellar or pontine hemorrhages were this large in the studied population). As hemorrhage volume increased, the patients' 30 -day mortality rates were significantly worse $(p<0.0001)$, indicating a strong predictive value of hemorrhage volume at presentation.

\section{Hematoma Expansion}

Another primary indicator of patient prognosis is expansion of the hematoma following the initial hemorrhagic insult. Clinically, it is challenging to assess for early hematoma expansion after the insult because of delayed presentation to the ED. However, most literature defines hematoma expansion as an increase in hematoma volume by $>33 \%$ [78]. 
Hematoma expansion has been reported in 38-76\% of patients within $3 \mathrm{~h}$ after the time of symptom onset and $26 \%$ of patients within $1 \mathrm{~h}$ after initial CT scan [6] as well as $50 \%$ of patients on anticoagulation $[33,79]$. Although the precise mechanism of hematoma expansion is unclear, it may be attributable to persistent bleeding or re-bleeding from the initial blood vessel rupture or new foci of bleeding at the periphery of the lesion, often attributed to ischemia, poor venous flow, and local coagulopathy [80, 81]. Large hematoma and a heterogeneous pattern can also be predictive of potential expansion $[82,83]$. The higher volume of hematoma expansion is associated with worse outcomes [79]. Recent ongoing research shows that certain radiographic markers, including the spot sign and swirl sign, are effective in identifying patients who are at risk for hematoma expansion and poor outcome.

\section{Spot Sign}

Utilizing postcontrast CT, a spot sign can be visualized as a focus of contrast extravasation in an expanding hematoma. It is a radiological marker that can indicate an active, ongoing hemorrhage in the brain parenchyma and help identify high-risk patients. Wada et al. [78] described the spot sign and its potential predictive value. In their study, 39 patients with spontaneous ICH were examined using postcontrast CT. Hematoma expansion occurred in 10 out of the 13 patients within this population that demonstrated the spot sign. The criterion for hematoma expansion was an increase in volume between 33 and 50\% [78]. Tsukabe et al. [84] collected similar data in another study. Postcontrast CT spot sign was observed in $24.1 \%$ of patients on admission and 53\% on follow-up. Presence of spot sign held a strong predictive value for hematoma expansion ( $p<0.001$ at admission and $p<0.00001$ on follow-up). Rizos et al. [85], in a prospective study of 101 patients, examined the predictive value of spot sign upon admission with regard to hematoma expansion and clinical outcome. $26.7 \%$ of patients exhibited a spot sign on admission in addition to higher initial hematoma volumes (36.0 vs. $14.39 \mathrm{~mL}, p=0.005$ ). At $24 \mathrm{~h}$ after ICH, patients with spot sign exhibited greater hematoma expansion $(p<0.001)$. However, no significant increase in the 3 -month outcome was found.

\section{Swirl Sign}

Similar to the spot sign, the swirl sign (detected on noncontrast CT) has been described as a marker of ongoing extravasation of blood within a hematoma. It is observed as a region of hypodensity within the hematoma that disrupts its uniformity. Hematomas that demonstrate the swirl sign are heterogeneously dense, a trait that Barras et al. [86] examined in their Randomized Controlled Trial. This study focused on the physical properties of ICHs upon presentation and demonstrated that there was a correlation between the size and density of hematomas and their propensity for expansion. In their study, they found that hematomas that were larger and more heterogeneous in density had greater growth between the baseline and 24-h CT scans [86]. A larger-scale retrospective analysis by Boulois et al. [7] showed similar results in a cohort of 1,029 patients with ICH. $52.8 \%$ of patients with hematoma expansion had observed hypodensities, whereas only $21.9 \%$ without hematoma expansion had hypodensities $(p<0.001)$. Using univariate analysis, warfarin use, presence of spot and swirl signs were significantly associated with hematoma expansion between two cohorts [7]. Selariu's group, examining the correlation of swirl sign with 30-day mortality rates, found similar results in a study of 203 patients. Swirl sign was seen in $30 \%$ of the population; 30-day mortality was $61 \%$ in patients demonstrating swirl sign compared to $21 \%$ of those not demonstrating it $(p<0.001)$.

\section{Perihematomal Edema}

These may develop as early as $1 \mathrm{~h}$ after ICH, show peak growth by 7 days, may last for weeks after injury, and have been associated with worse outcomes $[87,88]$. The mass created 
by the edema may contribute to the increased mortality rate and neurological deterioration. Between days 7 and 11 after ICH, PhE volume nearly doubled from 32.6 to $63.7 \mathrm{~mL}$, in a study done by Staykov et al. [88] $(n=219)$. They found that ICH volume strongly correlated with absolute PhE volume $(p<0.001)$. An increase in the absolute volume was found to be significantly associated with worse patient outcome and mortality rate. These findings are supported by the work done by Gebel et al. [87] who, in addition, noted that a larger baseline-relative edema volume (edema volume divided by hematoma volume) was associated with a significant decrease in poor 3-month outcome (OR 0.09 per 1 -mL increase, $p=0.016$ ). The etiology of this is likely multifactorial and includes blood-brain barrier damage, lysis of red blood cells, and white blood cell recruitment, in addition to release of plasma proteins, thrombin, hemoglobin, iron, matrix metalloproteinases, interleukins, and other inflammatory mediators [9, 25, 89-93].

\section{Intraventricular Hemorrhage}

IVH is present in about $45 \%$ of ICH patients. As blood fills the ventricular system, clots can form within the CSF leading to obstruction of CSF flow and consequently obstructive hydrocephalus and generalized edema [94]. IVH is consistently associated with worse outcomes across studies. It was found to be associated with a 2.6-fold increase in in the risk of early neurological deterioration in a study by Leira et al. [8]. IVH is an indicator of more severe ICH progression, and has been associated with better patient outcome when absent as compared to when present (31.4 vs. $15.1 \%, p<0.00001$ ). This is compounded by the presence of hydrocephalus, which decreases favorable outcome to $11.5 \%$. Favorable outcome is defined as functional independence and survival [95]. In a similar study, Hallevi et al. [96] identified IVH in $45 \%$ of their study population and examined incidence with regard to ICH location and volume, in addition to looking at patient outcomes. Larger ICH volumes were significantly associated with IVH presence $(p<0.001)$. Those presenting with IVH had a 2 -fold increase in poor outcome (OR 2.25, $p<0.001$ ). All relevant studies provide evidence that IVH is significantly associated with increased mortality and poor outcomes. Therapeutic intervention involving decompression and removal of blood from the ventricular system is of utmost importance in treatment of these patients [97].

\section{Hydrocephalus}

IVH occurs in $40 \%$ of patients with primary ICH, and is considered a predictor of poor outcome [98]. In a retrospective study by Herrick et al. [99], patients with lower GCS, severe IVH, and smaller ICH volume were more likely to have an external ventricular drain (EVD) placed. Placement of EVD was associated with reduced mortality and improved short-term outcomes after adjusting for severity factors.

Diringer et al. [100] first examined patients with ICH and their development of hydrocephalus after ictus. From the 81 patients studied, 40 developed hydrocephalus. Patients with hydrocephalus were younger ( 57 vs. 67) and more frequently had deep hemorrhages. Patients with hydrocephalus had a higher prevalence of ventriculostomy placement. Compared to those without hydrocephalus, those with had significantly higher 90-day mortality rates of $51 \%$ compared to $2 \%$ (OR 1.26, 95\% CI 1.13-1.42, $p<0.0001$ ). Presence of hydrocephalus in patients presenting with ICH is a serious complication and is a strong independent predictor of poor outcome. 


\begin{tabular}{l|l}
\hline DOI: $10.1159 / 000484571$ & $\begin{array}{l}\text { C } 2018 \text { S. Karger AG, Basel } \\
\text { www.karger.com/ine }\end{array}$ \\
\hline
\end{tabular}

Al-Mufti et al.: Clinical and Radiographic Predictors of Intracerebral Hemorrhage Outcome

\section{Conclusion}

Given the profound morbidity and mortality associated with ICH, these clinical and radiographic predictors of poor patient outcome are of important prognostic value. Currently, studies show that $<40 \%$ of patients regain functional independence after ICH, and mortality rate is $40 \%$ at 1 month and $54 \%$ at 1 year [2]. Indication of patient outcome, based on presentation upon admission, holds value when triaging patients and making care decision. Efforts can be made to provide effective intervention immediately to delay or prevent ensuing neurological damage. One concern with outcome prediction is that prediction of a high mortality rate may skew early decision-making and limit the care given to individuals who would otherwise be treatable. Due to this nature of outcome prediction, current care guidelines recommend aggressive initial treatment of all ICH patients regardless of factors present upon admission [17].

\section{Disclosure Statement}

All authors have no conflict of interest.

\section{References}

1 Qureshi AI, Tuhrim S, Broderick JP, Batjer HH, Hondo H, Hanley DF: Spontaneous intracerebral hemorrhage. N Engl J Med 2001;344:1450-1460.

2 van Asch CJ, Luitse MJ, Rinkel GJ, van der Tweel I, Algra A, Klijn CJ: Incidence, case fatality, and functional outcome of intracerebral haemorrhage over time, according to age, sex, and ethnic origin: a systematic review and meta-analysis. Lancet Neurol 2010;9:167-176.

3 Liotta EM, Prabhakaran S: Warfarin-associated intracerebral hemorrhage is increasing in prevalence in the United States. J Stroke Cerebrovasc Dis 2013;22:1151-1155.

4 Gonzalez-Perez A, Gaist D, Wallander MA, McFeat G, Garcia-Rodriguez LA: Mortality after hemorrhagic stroke: data from general practice (The Health Improvement Network). Neurology 2013;81:559-565.

5 Gebel JM, Broderick JP: Intracerebral hemorrhage. Neurol Clin 2000;18:419-438.

6 Brott T, Broderick J, Kothari R, Barsan W, Tomsick T, Sauerbeck L, Spilker J, Duldner J, Khoury J: Early hemorrhage growth in patients with intracerebral hemorrhage. Stroke 1997;28:1-5.

7 Boulouis G, Morotti A, Brouwers HB, Charidimou A, Jessel MJ, Auriel E, Pontes-Neto O, Ayres A, Vashkevich A, Schwab KM, Rosand J, Viswanathan A, Gurol ME, Greenberg SM, Goldstein JN: Association between hypodensities detected by computed tomography and hematoma expansion in patients with intracerebral hemorrhage. JAMA Neurol 2016;73:961-968.

8 Leira R, Davalos A, Silva Y, Gil-Peralta A, Tejada J, Garcia M, Castillo J: Early neurologic deterioration in intracerebral hemorrhage: predictors and associated factors. Neurology 2004;63:461-467.

9 Butcher KS, Baird T, MacGregor L, Desmond P, Tress B, Davis S: Perihematomal edema in primary intracerebral hemorrhage is plasma derived. Stroke 2004;35:1879-1885.

10 Ariesen MJ, Claus SP, Rinkel GJ, Algra A: Risk factors for intracerebral hemorrhage in the general population: a systematic review. Stroke 2003;34:2060-2065.

11 Bagg S, Pombo AP, Hopman W: Effect of age on functional outcomes after stroke rehabilitation. Stroke 2002; 33:179-185.

12 Sacco S, Marini C, Toni D, Olivieri L, Carolei A: Incidence and 10-year survival of intracerebral hemorrhage in a population-based registry. Stroke 2009;40:394-399.

13 Rost NS, Smith EE, Chang Y, Snider RW, Chanderraj R, Schwab K, FitzMaurice E, Wendell L, Goldstein JN, Greenberg SM, Rosand J: Prediction of functional outcome in patients with primary intracerebral hemorrhage: the FUNC score. Stroke 2008;39:2304-2309.

14 Elijovich L, Patel PV, Hemphill JC 3rd: Intracerebral hemorrhage. Semin Neurol 2008;28:657-667.

15 Moon JS, Janjua N, Ahmed S, Kirmani JF, Harris-Lane P, Jacob M, Ezzeddine MA, Qureshi AI: Prehospital neurologic deterioration in patients with intracerebral hemorrhage. Crit Care Med 2008;36:172-175.

16 Fan JS, Huang HH, Chen YC, Yen DH, Kao WF, Huang MS, Huang CI, Lee CH: Emergency department neurologic deterioration in patients with spontaneous intracerebral hemorrhage: incidence, predictors, and prognostic significance. Acad Emerg Med 2012;19:133-138. 
17 Hemphill JC 3rd, Greenberg SM, Anderson CS, Becker K, Bendok BR, Cushman M, Fung GL, Goldstein JN, Macdonald RL, Mitchell PH, Scott PA, Selim MH, Woo D: Guidelines for the management of spontaneous intracerebral hemorrhage: a guideline for healthcare professionals from the American Heart Association/American Stroke Association. Stroke 2015;46:2032-2060.

18 Hemphill JC 3rd, Newman J, Zhao S, Johnston SC: Hospital usage of early do-not-resuscitate orders and outcome after intracerebral hemorrhage. Stroke 2004;35:1130-1134.

19 Morgenstern LB, Zahuranec DB, Sanchez BN, Becker KJ, Geraghty M, Hughes R, Norris G, Hemphill JC 3rd: Full medical support for intracerebral hemorrhage. Neurology 2015;84:1739-1744.

20 Shepardson LB, Youngner SJ, Speroff T, Rosenthal GE: Increased risk of death in patients with do-not-resuscitate orders. Med Care 1999;37:727-737.

21 Weimer JM, Nowacki AS, Frontera JA: Withdrawal of life-sustaining therapy in patients with intracranial hemorrhage: self-fulfilling prophecy or accurate prediction of outcome? Crit Care Med 2016;44:1161-1172.

22 McCormick WF, Rosenfield DB: Massive brain hemorrhage: a review of 144 cases and an examination of their causes. Stroke 1973;4:946-954.

23 Thrift AG, McNeil JJ, Forbes A, Donnan GA: Risk factors for cerebral hemorrhage in the era of well-controlled hypertension. Melbourne Risk Factor Study (MERFS) Group. Stroke 1996;27:2020-2025.

24 Fisher CM: Pathological observations in hypertensive cerebral hemorrhage. J Neuropathol Exp Neurol 1971; 30:536-550.

25 Ziai WC: Hematology and inflammatory signaling of intracerebral hemorrhage. Stroke 2013;44(suppl 1):S74S78.

26 Dandapani BK, Suzuki S, Kelley RE, Reyes-Iglesias Y, Duncan RC: Relation between blood pressure and outcome in intracerebral hemorrhage. Stroke 1995;26:21-24.

27 Sakamoto Y, Koga M, Toyoda K: Systolic blood pressure after intravenous antihypertensive treatment and clinical outcomes in hyperacute intracerebral hemorrhage: the stroke acute management with urgent riskfactor assessment and improvement-intracerebral hemorrhage study. Stroke 2013;44:e153.

28 Tsivgoulis G, Katsanos AH, Butcher KS, Boviatsis E, Triantafyllou N, Rizos I, Alexandrov AV: Intensive blood pressure reduction in acute intracerebral hemorrhage: a meta-analysis. Neurology 2014;83:1523-1529.

29 Arima H, Anderson CS, Wang JG, Huang Y, Heeley E, Neal B, Woodward M, Skulina C, Parsons MW, Peng B, Tao QL, Li YC, Jiang JD, Tai LW, Zhang JL, Xu E, Cheng Y, Morgenstern LB, Chalmers J: Lower treatment blood pressure is associated with greatest reduction in hematoma growth after acute intracerebral hemorrhage. Hypertension 2010;56:852-858.

30 Hill MD, Muir KW: INTERACT-2: should blood pressure be aggressively lowered acutely after intracerebral hemorrhage? Stroke 2013;44:2951-2952.

31 Qureshi AI, Palesch YY: Antihypertensive Treatment of Acute Cerebral Hemorrhage (ATACH) II: design, methods, and rationale. Neurocrit Care 2011;15:559-576.

32 Granger CB, Alexander JH, McMurray JJ, Lopes RD, et al: Apixaban versus warfarin in patients with atrial fibrillation. N Engl J Med 2011;365:981-992.

33 Flibotte JJ, Hagan N, O'Donnell J, Greenberg SM, Rosand J: Warfarin, hematoma expansion, and outcome of intracerebral hemorrhage. Neurology 2004;63:1059-1064.

34 Rosand J, Eckman MH, Knudsen KA, Singer DE, Greenberg SM: The effect of warfarin and intensity of anticoagulation on outcome of intracerebral hemorrhage. Arch Intern Med 2004;164:880-884.

35 Culebras A, Messe SR, Chaturvedi S, Kase CS, Gronseth G: Summary of evidence-based guideline update: prevention of stroke in nonvalvular atrial fibrillation: report of the Guideline Development Subcommittee of the American Academy of Neurology. Neurology 2014;82:716-724.

36 Ruff CT, Giugliano RP, Braunwald E, Hoffman EB, Deenadayalu N, Ezekowitz MD, Camm AJ, Weitz JI, Lewis BS, Parkhomenko A, Yamashita T, Antman EM: Comparison of the efficacy and safety of new oral anticoagulants with warfarin in patients with atrial fibrillation: a meta-analysis of randomised trials. Lancet 2014;383:955962.

37 Wilson D, Seiffge DJ, Traenka C, Basir G, et al: Outcome of intracerebral hemorrhage associated with different oral anticoagulants. Neurology 2017;88:1693-1700.

38 Imberti D, Barillari G, Biasioli C, Bianchi M, Contino L, Duce R, D’Inca M, Mameli L, Pinna L, Ageno W: Prothrombin complex concentrates for urgent anticoagulation reversal in patients with intracranial haemorrhage. Pathophysiol Haemost Thromb 2008;36:259-265.

39 Goldstein JN, Thomas SH, Frontiero V, Joseph A, Engel C, Snider R, Smith EE, Greenberg SM, Rosand J: Timing of fresh frozen plasma administration and rapid correction of coagulopathy in warfarin-related intracerebral hemorrhage. Stroke 2006;37:151-155.

40 Frontera JA, Gordon E, Zach V, Jovine M, Uchino K, Hussain MS, Aledort L: Reversal of coagulopathy using prothrombin complex concentrates is associated with improved outcome compared to fresh frozen plasma in warfarin-associated intracranial hemorrhage. Neurocrit Care 2014;21:397-406.

41 Frontera JA, Lewin JJ 3rd, Rabinstein AA, Aisiku IP, Alexandrov AW, Cook AM, del Zoppo GJ, Kumar MA, Peerschke EI, Stiefel MF, Teitelbaum JS, Wartenberg KE, Zerfoss CL: Guideline for reversal of antithrombotics in intracranial hemorrhage: a statement for healthcare professionals from the Neurocritical Care Society and Society of Critical Care Medicine. Neurocrit Care 2016;24:6-46.

42 Manno EM: Update on Intracerebral Hemorrhage. CONTINUUM: Lifelong Learn Neurol 2012;18(3, Crit Care Neurol):598-610. 
43 Vespa PM, O’Phelan K, Shah M, Mirabelli J, Starkman S, Kidwell C, Saver J, Nuwer MR, Frazee JG, McArthur DA, Martin NA: Acute seizures after intracerebral hemorrhage: a factor in progressive midline shift and outcome. Neurology 2003;60:1441-1446.

44 Bladin CF, Alexandrov AV, Bellavance A, et al: Seizures after stroke: a prospective multicenter study. Arch Neurol 2000;57:1617-1622.

45 Passero S, Rocchi R, Rossi S, Ulivelli M, Vatti G: Seizures after spontaneous supratentorial intracerebral hemorrhage. Epilepsia 2002;43:1175-1180.

46 Mullen MT, Kasner SE, Messe SR: Seizures do not increase in-hospital mortality after intracerebral hemorrhage in the nationwide inpatient sample. Neurocrit Care 2013;19:19-24.

47 De Herdt V, Dumont F, Henon H, Derambure P, Vonck K, Leys D, Cordonnier C: Early seizures in intracerebral hemorrhage: incidence, associated factors, and outcome. Neurology 2011;77:1794-1800.

48 Messe SR, Sansing LH, Cucchiara BL, Herman ST, Lyden PD, Kasner SE: Prophylactic antiepileptic drug use is associated with poor outcome following ICH. Neurocrit Care 2009;11:38-44.

49 Naidech AM, Garg RK, Liebling S, Levasseur K, Macken MP, Schuele SU, Batjer HH: Anticonvulsant use and outcomes after intracerebral hemorrhage. Stroke 2009;40:3810-3815.

50 Honig A, Michael S, Eliahou R, Leker RR: Central fever in patients with spontaneous intracerebral hemorrhage: predicting factors and impact on outcome. BMC Neurol 2015;15:1-7.

51 Georgilis K, Plomaritoglou A, Dafni U, Bassiakos Y, Vemmos K: Aetiology of fever in patients with acute stroke. J Intern Med 1999;246:203-209.

52 Rincon F, Lyden P, Mayer SA: Relationship between temperature, hematoma growth, and functional outcome after intracerebral hemorrhage. Neurocrit Care 2013;18:45-53.

53 Castillo J, Davalos A, Marrugat J, Noya M: Timing for fever-related brain damage in acute ischemic stroke. Stroke 1998;29:2455-2460.

54 Schwarz S, Häfner K, Aschoff A, Schwab S: Incidence and prognostic significance of fever following intracerebral hemorrhage. Neurology 2000;54:354-261.

55 Hajat C, Hajat S, Sharma P: Effects of poststroke pyrexia on stroke outcome: a meta-analysis of studies in patients. Stroke 2000;31:410-414.

56 Greer DM, Funk SE, Reaven NL, Ouzounelli M, Uman GC: Impact of fever on outcome in patients with stroke and neurologic injury: a comprehensive meta-analysis. Stroke 2008;39:3029-3035.

57 Rincon F, Lyden P, Mayer SA: Relationship between temperature, hematoma growth, and functional outcome after intracerebral hemorrhage. Neurocrit Care 2013;18:45-53.

58 Broessner G, Beer R, Lackner P, Helbok R, Fischer M, Pfausler B, Rhorer J, Kuppers-Tiedt L, Schneider D, Schmutzhard E: Prophylactic, endovascularly based, long-term normothermia in ICU patients with severe cerebrovascular disease: bicenter prospective, randomized trial. Stroke 2009; 40:e657-e665.

59 Middleton S, McElduff P, Ward J, Grimshaw JM, Dale S, D’Este C, Drury P, Griffiths R, Cheung NW, Quinn C, Evans M, Cadilhac D, Levi C: Implementation of evidence-based treatment protocols to manage fever, hyperglycaemia, and swallowing dysfunction in acute stroke (QASC): a cluster randomised controlled trial. Lancet 2011;378:1699-1706.

60 Fogelholm R, Murros K, Rissanen A, Avikainen S: Admission blood glucose and short term survival in primary intracerebral haemorrhage: a population based study. J Neurol Neurosurg Psychiatry 2005;76:349-353.

61 Kimura K, Iguchi Y, Inoue T, Shibazaki K, Matsumoto N, Kobayashi K, Yamashita S: Hyperglycemia independently increases the risk of early death in acute spontaneous intracerebral hemorrhage. J Neurol Sci 2007;255: 90-94.

62 Passero S, Ciacci G, Ulivelli M: The influence of diabetes and hyperglycemia on clinical course after intracerebral hemorrhage. Neurology 2003;61:1351-1356.

63 Oddo M, Schmidt JM, Carrera E, Badjatia N, Connolly ES, Presciutti M, Ostapkovich ND, Levine JM, Le Roux P, Mayer SA: Impact of tight glycemic control on cerebral glucose metabolism after severe brain injury: a microdialysis study. Crit Care Med 2008;36:3233-3238.

64 Vespa P, Boonyaputthikul R, McArthur DL, Miller C, Etchepare M, Bergsneider M, Glenn T, Martin N, Hovda D: Intensive insulin therapy reduces microdialysis glucose values without altering glucose utilization or improving the lactate/pyruvate ratio after traumatic brain injury. Crit Care Med 2006;34:850-856.

65 Vespa PM: Intensive glycemic control in traumatic brain injury: what is the ideal glucose range? Crit Care 2008;12:175.

66 Tamhane UU, Aneja S, Montgomery D, Rogers EK, Eagle KA, Gurm HS: Association between admission neutrophil to lymphocyte ratio and outcomes in patients with acute coronary syndrome. Am J Cardiol 2008; 102:653-657.

67 Wang X, Zhang G, Jiang X, Zhu H, Lu Z, Xu L: Neutrophil to lymphocyte ratio in relation to risk of all-cause mortality and cardiovascular events among patients undergoing angiography or cardiac revascularization: a meta-analysis of observational studies. Atherosclerosis 2014;234:206-213.

68 Aronowski J, Zhao X: Molecular pathophysiology of cerebral hemorrhage: secondary brain injury. Stroke 2011;42:1781-1786.

69 Lattanzi S, Cagnetti C, Provinciali L, Silvestrini M: Neutrophil-to-lymphocyte ratio predicts the outcome of acute intracerebral hemorrhage. Stroke 2016;47:1654-1657.

70 Wang F, Hu S, Ding Y, Ju X, Wang L, Lu Q, Wu X: Neutrophil-to-lymphocyte ratio and 30-day mortality in patients with acute intracerebral hemorrhage. J Stroke Cerebrovasc Dis 2016;25:182-187. 
71 Sturgeon JD, Folsom AR, Longstreth WT Jr, Shahar E, Rosamond WD, Cushman M: Hemostatic and inflammatory risk factors for intracerebral hemorrhage in a pooled cohort. Stroke 2008;39:2268-2273.

72 Broderick JP, Brott TG, Duldner JE, Tomsick T, Huster G: Volume of intracerebral hemorrhage. A powerful and easy-to-use predictor of 30-day mortality. Stroke 1993;24:987.

73 O’Donnell HC, Rosand J, Knudsen KA, Furie KL, Segal AZ, Chiu RI, Ikeda D, Greenberg SM: Apolipoprotein E genotype and the risk of recurrent lobar intracerebral hemorrhage. N Engl J Med 2000;342:240-245.

74 Five-year findings of the hypertension detection and follow-up program. III. Reduction in stroke incidence among persons with high blood pressure. Hypertension Detection and Follow-up Program Cooperative Group. JAMA 1982;247:633-638.

75 Hussein HM, Tariq NA, Palesch YY, Qureshi AI: Reliability of hematoma volume measurement at local sites in a multicenter acute intracerebral hemorrhage clinical trial. Stroke 2013;44:237-239.

76 Kothari RU, Brott T, Broderick JP, Barsan WG, Sauerbeck LR, Zuccarello M, Khoury J: The ABCs of measuring intracerebral hemorrhage volumes. Stroke 1996;27:1304-1305.

77 Broderick JP, Brott TG, Duldner JE, Tomsick T, Huster G: Volume of intracerebral hemorrhage. A powerful and easy-to-use predictor of 30-day mortality. Stroke 1993;24:987-993.

78 Wada R, Aviv RI, Fox AJ, Sahlas DJ, Gladstone DJ, Tomlinson G, Symons SP: CT angiography “spot sign” predicts hematoma expansion in acute intracerebral hemorrhage. Stroke 2007;38:1257-1262.

79 Davis SM, Broderick J, Hennerici M, Brun NC, Diringer MN, Mayer SA, Begtrup K, Steiner T: Hematoma growth is a determinant of mortality and poor outcome after intracerebral hemorrhage. Neurology 2006;66:11751181.

80 Mayer SA, Lignelli A, Fink ME, Kessler DB, Thomas CE, Swarup R, Van Heertum RL: Perilesional blood flow and edema formation in acute intracerebral hemorrhage: a SPECT study. Stroke 1998;29:1791-1798.

81 Mayer SA: Ultra-early hemostatic therapy for intracerebral hemorrhage. Stroke 2003;34:224-229.

82 Barras CD, Tress BM, Christensen S, Collins M, Desmond PM, Skolnick BE, Mayer SA, Davis SM: Quantitative CT densitometry for predicting intracerebral hemorrhage growth. AJNR Am J Neuroradiol 2013;34:11391144.

83 Takeda R, Ogura T, Ooigawa H, Fushihara G, Yoshikawa S, Okada D, Araki R, Kurita H: A practical prediction model for early hematoma expansion in spontaneous deep ganglionic intracerebral hemorrhage. Clin Neurol Neurosurg 2013;115:1028-1031.

84 Tsukabe A, Watanabe Y, Tanaka H, Kunitomi Y, Nishizawa M, Arisawa A, Yoshiya K, Shimazu T, Tomiyama N: Prevalence and diagnostic performance of computed tomography angiography spot sign for intracerebral hematoma expansion depend on scan timing. Neuroradiology 2014;56:1039-1045.

85 Rizos T, Dörner N, Jenetzky E, Sykora M, Mundiyanapurath S, Horstmann S, Veltkamp R, Rohde S, Bendszus M, Steiner T: Spot signs in intracerebral hemorrhage: useful for identifying patients at risk for hematoma enlargement? Cerebrovasc Dis 2013;35:582-589.

86 Barras CD, Tress BM, Christensen S, MacGregor L, Collins M, Desmond PM, Skolnick BE, Mayer SA, Broderick JP, Diringer MN, Steiner T, Davis SM: Density and shape as CT predictors of intracerebral hemorrhage growth. Stroke 2009;40:1325-1331.

87 Gebel JM Jr, Jauch EC, Brott TG, Khoury J, Sauerbeck L, Salisbury S, Spilker J, Tomsick TA, Duldner J, Broderick JP: Relative edema volume is a predictor of outcome in patients with hyperacute spontaneous intracerebral hemorrhage. Stroke 2002;33:2636-2641.

88 Staykov D, Wagner I, Volbers B, Hauer EM, Doerfler A, Schwab S, Bardutzky J: Natural course of perihemorrhagic edema after intracerebral hemorrhage. Stroke 2011;42:2625-2629.

89 Levine JM, Snider R, Finkelstein D, Gurol ME, Chanderraj R, Smith EE, Greenberg SM, Rosand J: Early edema in warfarin-related intracerebral hemorrhage. Neurocrit Care 2007;7:58-63.

90 Power C, Henry S, Del Bigio MR, Larsen PH, Corbett D, Imai Y, Yong VW, Peeling J: Intracerebral hemorrhage induces macrophage activation and matrix metalloproteinases. Ann Neurol 2003;53:731-742.

91 Tejima E, Zhao BQ, Tsuji K, Rosell A, van Leyen K, Gonzalez RG, Montaner J, Wang X, Lo EH: Astrocytic induction of matrix metalloproteinase-9 and edema in brain hemorrhage. J Cereb Blood Flow Metab 2007;27:460-468.

92 Wagner KR: Modeling intracerebral hemorrhage: glutamate, nuclear factor-kappa B signaling and cytokines. Stroke 2007;38(suppl 2):753-758.

93 Xi G, Keep RF, Hoff JT: Mechanisms of brain injury after intracerebral haemorrhage. Lancet Neurol 2006;5: 53-63.

94 Yadav YR, Mukerji G, Shenoy R, Basoor A, Jain G, Nelson A: Endoscopic management of hypertensive intraventricular haemorrhage with obstructive hydrocephalus. BMC Neurol 2007;7:1.

95 Bhattathiri PS, Gregson B, Prasad KS, Mendelow AD: Intraventricular hemorrhage and hydrocephalus after spontaneous intracerebral hemorrhage: results from the STICH trial. Acta Neurochir Suppl 2006;96:65-68.

96 Hallevi H, Albright KC, Aronowski J, Barreto AD, Martin-Schild S, Khaja AM, Gonzales NR, Illoh K, Noser EA, Grotta JC: Intraventricular hemorrhage: anatomic relationships and clinical implications. Neurology 2008; 70: 848-852.

97 Gaberel T, Magheru C, Emery E: Management of non-traumatic intraventricular hemorrhage. Neurosurg Rev 2012;35:485-494; discussion 94-95. 
98 Steiner T, Diringer MN, Schneider D, Mayer SA, Begtrup K, Broderick J, Skolnick BE, Davis SM: Dynamics of intraventricular hemorrhage in patients with spontaneous intracerebral hemorrhage: risk factors, clinical impact, and effect of hemostatic therapy with recombinant activated factor VII. Neurosurgery 2006;59:767773; discussion 73-74.

99 Herrick DB, Ullman N, Nekoovaght-Tak S, Hanley DF, Awad I, LeDroux S, Thompson CB, Ziai WC: Determinants of external ventricular drain placement and associated outcomes in patients with spontaneous intraventricular hemorrhage. Neurocrit Care 2014;21:426-434.

100 Diringer MN, Edwards DF, Zazulia AR: Hydrocephalus: a previously unrecognized predictor of poor outcome from supratentorial intracerebral hemorrhage. Stroke 1998;29:1352-1357.

101 Ohwaki K, Yano E, Nagashima H, Hirata M, Nakagomi T, Tamura A: Blood pressure management in acute intracerebral hemorrhage: relationship between elevated blood pressure and hematoma enlargement. Stroke 2004;35:1364-1367.

102 Cucchiara B, Messe S, Sansing L, Kasner S, Lyden P: Hematoma growth in oral anticoagulant related intracerebral hemorrhage. Stroke 2008;39:2993-2996.

103 Van den Herik EG, Cheung EY, de Lau LM, den Hertog HM, Leebeek FW, Dippel DW, Koudstaal PJ, de Maat MP: Fibrinogen gamma' levels in patients with intracerebral hemorrhage. Thromb Res 2012;129:807-809.

104 Selariu E, Zia E, Brizzi M, Abul-Kasim K: Swirl sign in intracerebral haemorrhage: definition, prevalence, reliability and prognostic value. BMC Neurol 2012;12:109. 